\title{
Original Article \\ Elective Percutaneous Coronary Interventions (PCI) in 100 Cases in a Centre Without On-site Cardiac Surgery Support
}

\author{
Badrul MNA ${ }^{1}$, Ahmed $\mathrm{K}^{2}$, Rahman $\mathrm{S}^{3}$
}

\begin{abstract}
Since its introduction in 1977, Percutaneous Coronary Interventions (PCI) is an important tool in the treatment of coronary artery disease (CAD). It is a retrospective analysis of data of 100 cases (132 vessels). The mean age was 50.9 years (range 30-70) with 90 (90\%) male and 10 (10\%) female. Indication of PCI includes acute and old MI, Chronic stable angina and unstable angina were 48 (48\%), 33 (33\%) and 19(19\%) respectively. Procedure done in total 132 vessels among 100 patients. most of the cases were single vessels disease (SVD) \{68 (68\%\} followed by double vessel disease (DVD) $\{30(30 \%)\}$, triple vessel disease (TVD) $\{02(02 \%)\}$ and chronic total occlusion (CTO) $\{02(02 \%)\}$.Cobalt chromium was commonly used stent (117 (88.6\%) followed by drug illuting stent (DES) 12 (9.1\%) and bare metal stent (BMS) 3 (2.3\%). Among the site of the stent insertion left anterior descending (LAD) 62 (47\%), right coronary lesion (RCA) 37 (28), left circumplex artery (LCX) 33 (25\%).Maximum stent length was $35 \mathrm{~mm}$, minimum $10 \mathrm{~mm}$. Maximum stent diameter was $3.5 \mathrm{~mm}$ whereas minimum diameter $2.5 \mathrm{~mm}$. The mean pretreatment reference diameter was $2.55 \pm 0.20 \mathrm{~mm}$ and post treatment diameter $2.70 \pm 0.45$ mm. Angiographic, procedural and clinical success rate were 100\%, 98\% and 98\% respectively. Major adverse cardiovascular event (MACE) \{periprocedural MI\} occurred in $2(02 \%)$ cases. Minor cardiovascular complications revealed vascular haematoma $2(02 \%)$, bleeding from access site in $1(01 \%)$, transient ventricular fibrillation (VF) in 3 (03\%) cases. There was no hospital death, emergency CABG before discharge from hospital. Angiographic, procedural and clinical success rate were excellent with a little MACE and event free survival within 30 days follow up. So, PCI is a safe and effective method of myocardial revascularization irrespective of lesion morphology and type of stents used at immediate and 30 days follow up.
\end{abstract}

\section{Introduction}

In 1977 A.D German cardiologist Andreas Gruentzig (1939-85) introduce Percutaneous trans-luminal coronary angioplasty (PTCA) as a non surgical procedure used to dilate narrowed coronary arteries ${ }^{1}$. This procedure is now referred to as Percutaneous coronary intervention (PCI) as this term include the use of balloon, insertion of intra coronary stent and atherectomy device. Since it's introduction, PCI has dramatically changed the modalities of treatment in coronary artery disease (CAD) and effectively replace the need for coronary artery bypass graft surgery $(\mathrm{CABG})^{2}$.

1. Corresponding Author: Dr. Md Nurul Afsar Badrul, MBBS, D-Card
Assistant Professor, Department of Cardiology
North-East Medical College, Sylhet
2. Dr. Kamal Ahmed
Assistant Professor, Department of Medicine
North-East Medical College, Sylhet
3. Professor (Emeritus) Dr. Sufia Rahman
Department of Cardiology
North-East Medical College, Sylhet

Now a days stent insertion along with angioplasty is a routine procedure in treatment of CAD because evidence suggest that stent implantation enhances the procedural success and durability of angioplasty. With the operator experience, new technology and adjunctive pharmacotherapy the overall success and complication rate of PCI have improved ${ }^{3}$. This modern effective procedure is introduce in our country for a last few years. As far our knowledge, regarding outcome of this procedure no complete study were done in peripheral cath centre of Bangladesh rather than a few study were conducted centrally. North east medical college hospital $(\mathrm{NEMCH})$ is a medical institute in Sylhet, Bangladesh has a well established cath lab centre in cardiology unit were routinely performed coronary angiogram (CAG), percutaneous trans-luminal mitral commissurotomy and PCI etc. This study is a result of immediate outcome of percutaneous coronary intervention (PCI) in 100 cases of this newly setup cath centre.

\section{Materials and Methods}

100 consecutive cases of males and females, who attended in the department of Cardiology, North east Medical college Hospital (NEMCH), Sylhet, from August 2008 to September 2009 , were included in this study. Involved patients were selected on the basis of inclusion and exclusion criteria as mentioned below. The study was approved by the review committee of the Medical College.

1. Study population

1.a:Study design

Retrospective observational study

1.b. Inclusion criteria

100 consecutive patients who have undergone coronary stenting were taken as study population. Informed consent was taken from all patients.
1.c. Exclusion criteria's
1. Left main lesion
2. Stent re-stenosis
3. Bifurcation lesion
4. Pregnant women
5. Contraindication for aspirin and clopidegrol therapy

\section{Study procedure}

Before stent implantation, patient were treated with aspirin $300 \mathrm{mg}$ and clopidogrel $300 \mathrm{mg}$ at least $12 \mathrm{hrs}$ before the procedure. A bolus of 10000 unit heparin was given after sheath insertion, with repeat boluses of heparin given as needed to maintain an ACT $>250 \mathrm{sec}$. Different typed (BMS, cobalt, DES) of stents were used. All stents were premounted on a delivery system. Most of the stents were inflated at high pressure $(>14 \mathrm{~atm})$ for final in stent dilatation. Post dilatation were performed within the stent to obtain a near zero residual stenosis in few cases. After stent implantation, patient were treated with heparin, started 2 to 3 hrs after sheath removal and continue for $12 \mathrm{hrs}$ in uncomplicated cases and $48 \mathrm{hrs}$ in CTO. Clopidogrel $150 \mathrm{mg}$ was given for 12 months and aspirin $150 \mathrm{mg}$ indefinitely. 
The vessel and lesions were analyzed using a computerized quantitative analysis system (QCA-CMS version). Measurement included the interpolated reference diameter, minimal luminal diameter, percent diameter, percent diameter stenosis and lesion length were obtained from the angiogram at baseline and after stent implantation. Lesions were characterized according to the modified AHA/ACC classification. Figure 1 showed Balloon dilatation and placement of stent in the site of atherosclerotic segment.

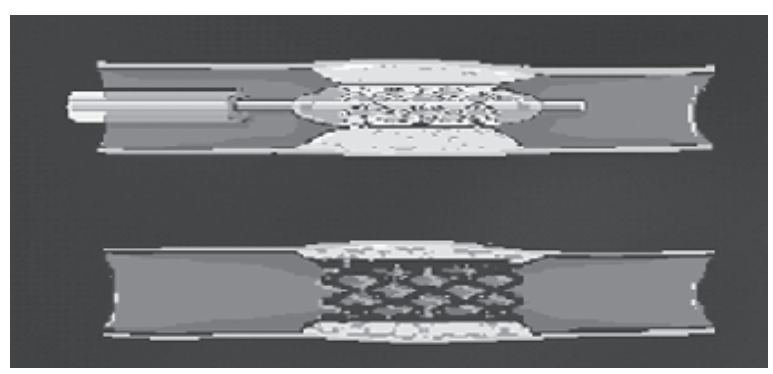

Figure 1- Balloon dilatation and placement of stent in the site of atherosclerotic segment.

Clinical events were monitored during hospital stay and at 30 days out patient visit. Patients were seen at outpatient clinic or a direct telephone interview. Anginal pain was characterized according to Canadian cardiovascular society classification. Clinical follow up ended when patient developed cardiovascular adverse event (MACE).

\section{Definition}

I. Angiographic success

A successful PCI procedure includes- substantial enlargement of the lumen at the target site with the achievement of a minimum stenosis diameter reduction to $20 \%$ in the presence of grade 3 TIMI flow (assessed by angiography).

\section{Procedural success}

A successful PCI should achieve angiographic success without in hospital major clinical complications (e.g. death, MI, emergency CABG, during hospitalization).

\section{Clinical success}

A clinically successful PCI includes anatomic and procedural success with relief of signs and or symptoms of myocardial ischaemia after the patient recovers from procedure.

\section{Procedural complications}

These are divided into six basic categories:
i. Death
ii. MI
iii. Emergency $\mathrm{CABG}$
iv. Stroke
v. Vascular access site complication
vi. Contrast agent nephropathy

\section{Statistical analysis}

After processing all available information, statistical analysis and their significance were done by SPSS program. Categorical values were presented as absolute numbers (percentage), continuous values as mean \pm SD. ' $\mathrm{P}$ ' value of less than 0.05 was considered to be significant.

\section{Results}

Total Number of patients studied -100

Age distribution

Mean age -50.9 (range 30-70 yrs)

Types of the vessels have undergone PCI

(Procedure done in total 132 vessels in 100 patients)

Table-1: shows number \& percentage of vessel undergone PCI

\begin{tabular}{|l|c|c|}
\hline \multicolumn{1}{|c|}{ Vessel type } & No. of vessel & Percentage \\
\hline SVD & 90 & $68 \%$ \\
\hline DVD & 37 & $28 \%$ \\
\hline TVD & 03 & $02 \%$ \\
\hline $\begin{array}{l}\text { Chronic total occlusion } \\
\text { (CTO) }\end{array}$ & 02 & $01 \%$ \\
\hline Total & 132 & $\approx 100 \%$ \\
\hline
\end{tabular}

Sites of stent insertion:

Table-2: shows number $\&$ percentage of sites of vessel

\begin{tabular}{|c|c|c|}
\hline Site of vessel & No. & Percentage \\
\hline LAD & 62 & $47 \%$ \\
\hline RCA & 37 & $28 \%$ \\
\hline LCX & 33 & $25 \%$ \\
\hline Total & 132 & $100 \%$ \\
\hline
\end{tabular}

Types of stent used in 132 vessels

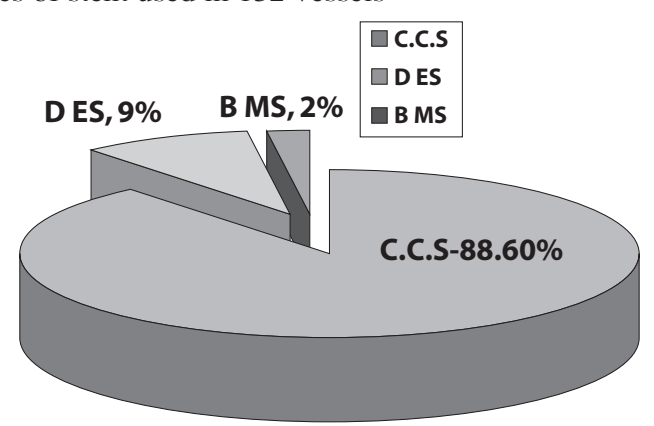

Fig- 2: Pie diagram shows types of stent used.

Success rate

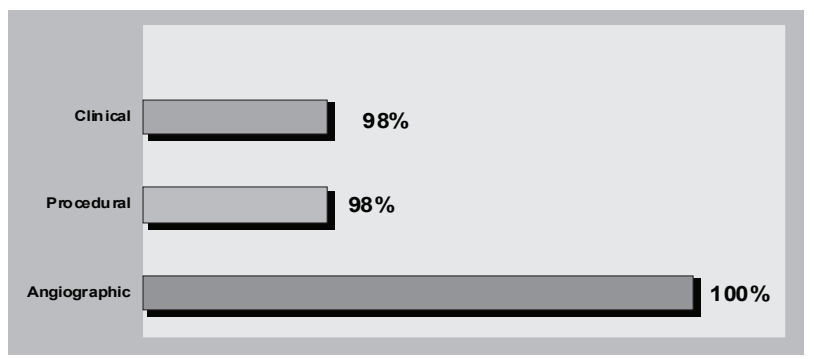

Fig- 3: Bar diagram showing success rate of PCI in 100 cases Complications of PCI: (N-100=100\%)

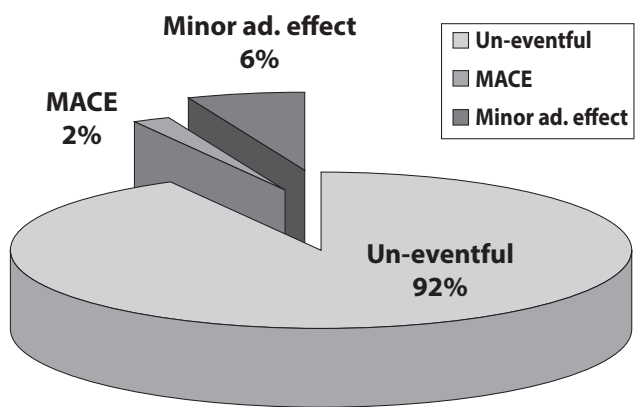

Fig- 4: Pie diagram showing type of complications of PCI in 100 cases 


\section{Discussion}

Now a days, during performing percutaneous coronary revascularization, supplementation of a stent is a routine practice $^{4}$. Study reveals that stent implantation enhances the procedural success and durability of angioplasty in term of reduction in the incidence of lesion recurrence and reduced need for repeat revascularization and lower rates of peri-procedural myocardial infarction $(\mathrm{MI})^{5-8}$.

Patient enrolled in this study were the routine patients admitted in NEMCH with acute chest pain suggestive of acute coronary syndrome (ACS) and stabilization by medical therapy for at least 3 days, known IHD patient for routine PCI and patient admitted with a view to CAG and subsequently consent for PCI were include in this study.

The main objective of this of this study is an attempt to summarize the initial experience of PCI in 100 consecutive patients with emphasis on clinical success and MACE starting from the procedure \& upto 30 days follow- up in a peripheral cath lab of Bangladesh. The outcomes of PCI depend on many factors but patient selection \& technical skills play most important role of all.

In this study the major finding is angiographic, procedural and clinical success were $100 \%, 98 \%$ and $98 \%$ respectively achieved in 132 lesions with minor adverse effect $06 \%$ \& MACE is $02 \%$. No procedure related death at 30 days follow up. Results of this study are generally consistent with most of the published literature as regards the immediate and short term outcomes. Rahman ${ }^{9}$ in 2004 reported 96\% clinical success with $2 \%$ mortality. Reported angiographic success rates ranged from as low as $59 \%{ }^{10}$ in the early days of 1970 s to as high as $100 \%{ }^{11}$ during the 2008 A.D. Though angiographic success was better among the patients with single vessel disease (SVD) than patients with multi-vessel disease but in this study angiographic success 100\% irrespective of vessel involved which is similar to shahabuddin ${ }^{11}$ study. Although intracoronary stents had a dramatic impact on reduction of acute complications after PCI yet in present study complications during the procedure as non fatal MI occurred in 2 patients $(02 \%) \&$ no death occurred. Ce Bredlau ${ }^{12}$ and Uddin $^{13}$ reported overall myocardial infarction rate was $2.6 \%$ \& mortality rate $01 \%$. These results are consistent with our present study, but mortality rate is $00 \%$ in present study may be due to expertisation of investigator. Eechout ${ }^{14}$ in 1996 \& Serruys ${ }^{15}$ in 1994 reported the main limitation of coronary stenting is sub-acute in-stent thrombosis occurred in 4 patients $(2 \%)$ which leading to myocardial infarction. Braim M Rahel ${ }^{16}$ reported $1 \%$ instant thrombosis \& Islam $^{17}$ in 2003 reported $0 \%$ instant thrombosis in their series of $100 \& 60$ patients respectively.With the improvements in procedural success due to stents and newer pharmacological strategies, there has been a reduction in complications and the need for emergency $\mathrm{CABG}$ with current rates $00 \%$ in this study to $0.3 \%$ in other investigators ${ }^{3}$.

The present study provides a relatively short period follow-up. Event free survival at 30 days was present in 92 patients $(92 \%)$ which are almost similar to many national and international studies ${ }^{11,18-21}$.
The findings of the present study support the previous reports of high angiographic, procedural \& clinical success with low in-hospital complications and high survival after PCI. PCI is safe and effective method in myocardial revascularization irrespective of lesion morphology, type of stent used and risk factor of patients immediate \& 30 days clinical follow up.

\section{References}

1. Gruntzig A.Transluminal dilatation of coronary artery stenosis. Lancet. 1978;1:263.

2. Drathuraria N, Bernhard M. Treatment of in-stent restenosis. The medical device manufacturing \& technology. 2004;954.

3. Timothy J, Gardner, Gabriel G, Richard 0, Russell C, Smith jr et al. Guidelines for Percutaneous Coronary Intervention. Circulation. 2001;103:3019-3041.

4. Batieha A, Dabbas M, Fraihat M, Jaddou H, Hiari A, Qussous Y. Percutaneous translurninal coronary Angioplasty: 13.5 Years of follow up. J Clin Basic Cardiology. 2001;4:285-8.

5. Detre K, Holubkov R, Keisey S. Percutaneous transluminal coronary angioplasty-National Heart, Lung, and Blood registry. N Engl J Med. 1988; 318:265-70.

6. Henderson RA, Raskino C, Karani S, Sowton E. Comparative long-term results of coronary angioplasty in single and multi-vessel disease. Eur Heart J. 1992;13:781-6.

7. Bredlau CE, Roubin GS, Leimgruber PP, Douglas JS, Junior SB King, Gruentzig AR. In-hospital morbidity and mortality in patients undergoing elective coronary angioplasty. Circulation. 1985;72:1044-1052.

8. Tenberg JM, Gin MT, Ernst SM, Kelder JC, Suttorp MJ, Mast EG et al. Ten year follow-up of percutaneous transluminal coronary angioplasty for proximal left anterior descending coronary artery stenosis in 351 patients. Am Coll Cardiol. 1996;28:82-8.

9. Rahman A, Ali M, Mojumder AAS. Immediate outcome of percutaneous coronary interventions in patients aged 45 years or less. Bangladesh Heart Journal. 2004;19:36-40.

10. Hochberg MS, Levine FH, Daggett WM, Akins G, Buckley MJ. Complicated coronary artery bypass grafting in patients seventy years of age and older. J cardiovasc Surg. 1982;84:219-23.

11. Shahabuddin M. Immediate and short term outcome of PCI in 200 cases-the initial experience. Bangladesh heart j. 2008;23:10-15.

12. Bredlau CE, Roubin GS, Leimgruber PP, Douglas JS, Junorr SB King, Gruentzig. In- hospital morbidity and mortality in patients undergoing elective coronary angioplasty. Circulation. 1985;72:1044-1052.

13. Uddin MJ, AIi M, Islam KQ, chowdhury AHK, Rahman F, Hasan KA et al. Short term outcome (in hospital) of 300 cases of percutaneous coronary intervention. University Heart journal. 2005;1:61-67. 
14. Eeckhout E, Kappenberger L, Goy JJ. Stents for intracoronary placement: Current status and future directions. J Am Cardiol. 1996;27:752-65.

15. Serruys PW, Jaegere P, Kiemeneij F. A comparison of balloon expandable stent implantation with balloon angioplasty in patients with coronary artery disease. N Eng J Med. 2005;25:35-37.

16. Braim M, Rahel MJ, Suttorp HA, Rieie M, Egbert T, Sjef MP, et al. Stenting for restenotic lesions with the BARD XT stent. Journal of interventional Cardiology. 2003;16:227-230.

17. Islam MS, Majumder AAS, Rahman S. Influence of balloon and stent on initial success- acute complications and restenosis after percutaneous transluminal coronary angioplasty. Bangladesh heart journal. 2003;18:21-28.
18. Ali M, Momen A, Shahabuddin M, Ahmed AFK, Karmakar PK, Hossain MS et al. Immediate outcome of PCI in a single calendar Year.Bangladesh Heart Journal. 2008;23:10-17

19. King SB, Schiumpf M. Ten-year completed follow-up of percutaneous transluininal coronary angioplasty- The early zuric experience. J Am Coil Cardiol $1993 ; 22: 535-60$.

20. Califf RM, Tomabechi Y, Lee KL, Phillips H, Pryor DB, Harreli FE et al. Outcome in one vessel coronary artery disease. Circulation. 1993;67:283-90.

21. Sharaf B, Riley RS, Drew TM, Williams Do. Late (five to eight years) clinical and angiographic assessment of patients undergoing successful percutaneous coronary angioplasty. AM j Cardiol. 1992;69:965-7. 